Otros Estudios 



\title{
EREBEA
}

Revista de Humanidades

y Ciencias Sociales

NúM. 6 (2016), pp. 253-272

ISSN: 0214-0691

\section{La Atlántida de Platón: aproximación a la Historia del RELATO, DESDE EL RENACIMIENTO HASTA NUESTROS DÍAS}

\author{
José Orihuela Guerrero \\ Universidad de Huelva
}

RESUMEN

En el presente artículo se realiza, desde el Renacimiento hasta nuestros días, un recorrido por las diversas hipótesis que se han vertido en torno al relato platónico sobre la Atlántida, formuladas por una serie de autores de muy diferente formación académica e intencionalidad ideológica. Y ese recorrido histórico nos muestra que el de la Atlántida puede considerarse un relato-problema que ha ido reformulándose a lo largo del tiempo para cumplir diversas funciones a lo largo de su dilatada historia, una de ellas sin duda la de servir de instrumento para cuestionar los paradigmas dominantes en las diversas etapas que comprende el período histórico referenciado, incluso alejándose para ello en muchas ocasiones de lo sostenido en el texto elaborado por el pensador ateniense. Termina el artículo consignando una serie de puntos acerca del papel que el relato platónico sobre la Atlántida podría jugar en la actualidad.

Palabras Clave

Atlántida; Análisis Cultural; Antropología Social y Cultural; Historia de la Filosofía; Geografía Histórica.

Fecha de recepción: 16 de nov. de 2015

Fecha de aceptación: 21 de abril de 2016

\section{Abstract}

This article presents a journey, from the Renaissance to the present day, through the different hypotheses made about the Platonic story of Atlantis and proposed by a number of authors from very different academic backgrounds and ideological intents. This historical overview shows that Atlantis can be considered a story/problem that has been reformulated over time to serve many roles throughout its long history. One of them, undoubtedly, to be instrumental when it comes to questioning the dominant paradigms at the various stages comprising the referenced historical period, even, in order to do so, moving away on many occasions from what the text written by the Athenian thinker contains. The article ends by stating a number of points about the role that the Platonic story of Atlantis could play today.

\section{Keywords}

Atlantis; Cultural Heritage; Social and Cultural Anthropology; History of Philosophy; Historical Geography. 

A lo largo de los siglos transcurridos desde que Platón escribió sus diálogos Timeo y Critias hasta el momento actual, múltiples y diversas personalidades se han ocupado del tema de la Atlántida. Y tanto los escépticos por un lado como los detractores por otro, así como los fervientes partidarios de la existencia histórica real de la isla imperial por su parte, parecen estar de acuerdo en dividir en dos grandes campos a las personas que a lo largo de la historia se han ocupado del tema: el de los científicos y el de aquellos que no lo son.

En un libro publicado en 1969 y titulado The Mystery of Atlantis -"El Misterio de la Atlántida"-, Charles Berlitz dedica un capítulo a hablarnos de las opiniones vertidas acerca del continente perdido y lo titula La Atlántida y los Cientificos, si bien no menciona precisamente a muchos científicos a lo largo del capítulo. A partir de aquí prosigue Berlitz con un texto que reproducimos porque resume perfectamente el juicio que a los no científicos les merece el escepticismo de los círculos académicos hacia el tema que nos ocupa:

"La comunidad académico-histórica oficial y, en menor grado, el mundo científico, han observado desde hace tiempo el problema de la Atlántida con escepticismo, incredulidad e incluso hilaridad. Los historiadores, como es natural, muestran muy poco entusiasmo por la 'historia intuitiva', basada en 'memorias de raza', que es la base de una gran parte de la literatura que se ha vertido acerca de la isla de Platón. Además, cualquier examen serio de la teoría atlántica, incluso si estuviera fundamentado en lo que ya ha sido descubierto, echaría por tierra muchos de los dogmas existentes acerca de la civilización primitiva y obligaría a una reelaboración de nuestra historia antigua." ${ }^{1}$

En este texto vemos una argumentación estándar de los partidarios de una investigación sobre el tema no sujeta a los constreńimientos de la ciencia y partidarios por el contrario de una llamada historia intuitiva. Se comienza expresando la prepotencia y suficiencia con que la ciencia oficial rechaza el asunto para a continuación dejar caer que ello ocurre porque en el fondo existe un temor

1 Berlitz, Charles: El Misterio de la Atlántida. Pomaire. Barcelona, 1969, pp. 183-184. 
a que se desmorone un paradigma que hace aguas por muchos sitios. Por último se termina expresando la confianza en que las nuevas técnicas científicas ayuden a acabar con tal cerrazón mental y se logre alcanzar un acuerdo entre la ciencia y lo que no lo es. Y para demostrar que la cerrazón del mundo académico no es algo nuevo, sino una constante de la historia de la ciencia, se recurre a todos aquellos casos en que efectivamente la ciencia oficial tuvo que admitir hechos que en principio no encajaban en el paradigma dominante en su época. $\mathrm{Y}$ al final se hace inevitable la referencia al celebérrimo Heinrich Schliemann y su descubrimiento de Troya siguiendo al pie de la letra el texto de Homero, en contra de la opinión de todas las eminencias científicas de su época.

"En arqueología, además de los casos de Pompeya y Herculano, en que los descubrimientos reivindicaron la leyenda, habría que señalar también las dudas muy generalizadas que existían acerca de los informes sobre 'ciudades indígenas perdidas' en la jungla de América Central antes de su descubrimiento en el siglo XIX y antes del verdadero furor arqueológico que los hallazgos desencadenaron. Por otra parte, durante mucho tiempo se creyó que las inscripciones persas, babilónicas y asirias del Oriente Medio eran elementos decorativos, y no signos de un lenguaje escrito, hasta que fueron descifradas y proporcionaron una historia detallada de una zona que los habitantes nativos de la época habían ignorado u olvidado por completo...Tal vez la más notable de todas las evidencias obtenidas en arqueología fue la de Heinrich Schliemann, quien, en 1871, descubrió Troya..."

Lo cierto es que, como el propio Berlitz reconoce, el diálogo entre los representantes del paradigma científico dominante y los seguidores de la historia intuitiva -expresión que utilizamos para seguir la terminología que propone este autor- es harto difícil, y la mayoría de las veces por razones no precisamente imputables a los miembros de la comunidad científica.

AtLANTis y AmÉrica.

Pero si el tema de la Atlántida suscitó interés en la antigüedad clásica y pasó prácticamente desapercibido durante la Edad Media, el descubrimiento de América volvió a ponerlo en primer plano. Los hombres de los siglos XVI y XVII solo poseían dos paradigmas explicativos con los que intentar asumir ideológicamente tamaña alteración de sus conocimientos geográficos: la tradición pagana y la Biblia. En efecto, a nadie se le puede ocultar la afirmación de Platón 
acerca de que desde Atlantis se puede ir de isla en isla hasta el verdadero continente que cierra el mar-Timeo, 24e-25a- y que para muchos constituye una prueba inequívoca de que una parte del relato platónico conecta con el conocimiento de la existencia de América en el mundo antiguo.

Marsilio Ficino tradujo Critias en 1485 y Pedro Mártir de Anglería afirmó en 1493 que Colón había descubierto un nuevo mundo que nada tenía que ver con el continente asiático. Ya Francisco López de Gomara, en su Historia General de las Indias (1522), señaló la admirable identidad existente entre el relato platónico y el nuevo continente e incluso expuso similitudes filológicas como el hecho de que en México agua se designe con el término atl -raíz de Atlantis-. Respecto a la influencia del relato de la Atlántida en la epopeya colombina, es interesante observar que mientras Gonzalo Fernández de Oviedo la afirma rotundamente en su obra Historia General y Natural de las Indias (1535), Hernando de Colón -hijo del Almirante de la Mar Océana- niega cualquier interés de su padre por el asunto. Claro que ignoramos si lo hizo por evitar más problemas a la memoria de su progenitor con la ortodoxia católica establecida, o porque constató -al igual que en el siglo XIX hará Humboldt- la ausencia de referencia alguna a la isla platónica en la obra escrita del descubridor -por otro lado, celoso custodio de las fuentes que tanto le habían convencido sobre el seguro éxito de su empresa-.

En su Historia de las Indias de 1527 Bartolomé de las Casas sostiene que no es descabellado pensar que una parte del continente descrito por Platón hubiese escapado al cataclismo, y en 1530 Gerolamo Fracastore relaciona directamente a los indios con los supervivientes de la Atlántida. En 1580 aparece la obra póstuma de Goropius Becanus, Hispanica, donde enlaza el relato platónico y el mito de las diez tribus perdidas de Israel para justificar los derechos de la corona de Espańa sobre el continente americano al convertir a Tartessos en la capital de la antigua Atlantis. En la misma línea se va a pronunciar en 1572 Pedro Sarmiento de Gamboa en su obra Historia General llamada Índica.

Contra esta unión del paradigma bíblico y el pagano con objeto de legitimar los derechos del imperio español se pronunciará José de Acosta, que en 1589 publica una Historia Natural y Moral de las Indias Occidentales donde rechaza la identificación del continente descubierto por Cristóbal Colón tanto con el relato platónico como con el mito de las diez tribus, afirmación que será secundada por el francés Michel de Montaigne.

Podemos observar en esta irrupción del tema atlante en la Edad Moderna cómo el relato es asumido en el marco ideológico y político dominante en la época y desplaza el interés de los que lo trataban en el mundo antiguo con objeto de elucidar la verdad geográfica o geológica -o apuntalar sus opiniones acerca de esas cuestiones- hacia asuntos muy distintos. En efecto, en los albores de esta nueva época el tema de la Atlántida va a verse sumergido por una parte en la pugna renacentista entre la teología bíblica y la herencia cultural del mundo clásico 
como paradigmas alternativos para dirigir la cultura humana. Pero también la hipotética existencia de la isla imperial se constituye en un poderoso argumento de legitimación política en manos de la monarquía dominante en la época. Estos dos ejes de conflicto harán que entre los partidarios de la Atlántida encontremos fundamentalmente a historiadores de la corte española y de su esfera de influencia por un lado y a humanistas preclásicos por otro, mientras que el bando de los detractores estará poblado fundamentalmente por los exégetas de la tradición judeocristiana y los enemigos del expansionismo español.

Atlantis, la Utopía y el Tiempo.

Junto a esta doble confrontación, la Atlántida también va a servir a otros autores como pretexto para exponer sus ideas acerca de la organización de la sociedad. Atlantis será de este modo inspiradora de utopías, e inevitablemente este rasgo asociado a lo ideal e inexistente en la realidad se le adherirá en esta época al relato platónico de forma casi definitiva. A ello contribuirá sin duda la obra de Francis Bacon titulada Nueva Atlántida -publicada póstumamente en 1627-. Es el relato de un viaje a los Mares del Sur, a una tierra que por definición está en $u$-topos -es decir, en ninguna parte- y donde se ha creado una especie de síntesis social entre el avance científico y el puritanismo religioso.

Otra cuestión de capital importancia es la que concierne al horizonte temporal en que nos sitúa el relato platónico de la Atlántida, y ello por un doble motivo. En primer lugar por su enorme trascendencia en lo que afecta a la apertura del campo de estudio de las ciencias históricas; y en segundo lugar porque constituye una prueba más de la enorme potencia creativa y sugeridora de ideas nuevas que tiene el texto. Alguien tan poco sospechoso de simpatizar con la veracidad de lo narrado por Platón como Pierre Vidal-Naquet nos dice lo siguiente:

“¿Tuvo la lectura del relato platónico, en el siglo XVII, influencia sobre la expansión del tiempo? Para mi sorpresa, debo dar una respuesta positiva. Para expandir el tiempo, había que liquidar la cronología bíblica, ya sea demostrando que Adán no había existido, ya sea probando que había habido hombres antes de Adán.” ${ }^{3}$

Fue el nacionalista francés Isaac La Peyrère quién en 1655 publicó Préadamites, obra en la que utiliza el dato de que la guerra entre los atlantes y los atenienses se produjo nueve mil años antes de nuestra era para demostrar que habían existido hombres antes de Adán y que por consiguiente el estrecho marco de la cronología bíblica -apenas cuatro mil años antes del advenimiento de Cristo- debía ser revisado.

3 Vidal-Naquet, P.: La Atlántida. Pequeña Historia de un Mito Platónico. Akal. Madrid, 2006, p. 76 . 
Las implicaciones de tal punto de vista son enormes. De hecho abren paso a una concepción evolucionista de la historia que será la que adopte la Ilustración francesa del siglo siguiente y más tarde el conjunto de las ciencias biogeológicas, con las consecuencias científicas y culturales de todos conocidas. Y no debemos dejar de apuntar que, del mismo modo que la mención a un continente que cierra el mar parece constituir una clara alusión al conocimiento de la existencia de América, esa fecha de nueve mil años antes de Solón constituye una referencia a acontecimientos ocurridos al final de la era glacial y de los que las fuentes en que se basara Platón al parecer tenían algún tipo de referencia. ¿Cómo es ello posible? Sin duda este punto constituye otro de los grandes enigmas que provoca el relato que nos ocupa.

\section{Atlantis y el Nacionalismo.}

Si nos fijamos ahora en el segundo aspecto de la pugna ideológica y política en que el texto de Platón se vio inmerso en los comienzos de la Edad Moderna podremos entender la siguiente dimensión que nos va a presentar la apropiación de la historia de Atlantis, a saber, la reafirmación nacionalista. Ya vimos cómo la utilizaron en ese sentido los escritores de la corte madrileńa, y de hecho La Peyrère era un nacionalista galo que pensaba que el rey de Francia estaba llamado a conseguir la hegemonía universal. Pues bien, este "nacional-atlantismo" -término que tomamos de Vidal-Naquet- será desarrollado también en Suecia por Olaus Rudbeck, cuya gigantesca obra -titulada Atlantica, sive Manheim, vero Japheti posterorum sedes ac Patria- fue publicada entre 1679 y 1702 . Sostiene en ella que Suecia es la patria de la posteridad de Jafet y la verdadera Atlántida -cuya capital se encontraba en la actual Upsala-, siendo las runas los precedentes del alfabeto fenicio y griego.

Sin embargo, sigue habiendo en el siglo XVII autores que tratan el tema de la Atlántida sin buscar en ella los asientos originarios de su patria. Es el caso del jesuita alemán Atanasius Kircher (1602-1680) autor de Mundus Subterraneus (1664) y de la famosa cartografía que ilustra tantos libros sobre el tema donde sitúa a la Atlántida como una isla en el centro del Atlántico, y que entre otras cosas sostuvo que las islas Canarias eran los vestigios del hundimiento y los guanches los descendientes de los supervivientes de la población atlante.

\section{Atlantis y la Biblia}

Volvamos a la relación entre el relato de la Atlántida como estandarte del paradigma clásico frente al paradigma bíblico con que comienza la utilización del relato de Platón en la Edad Moderna. Esta relación es fundamental y rebrota con fuerza en el siglo XVIII, según nos dice Vidal-Naquet: 
"La cuestión que me gustaría abordar ahora anida en el corazón de la empresa 'filosófica'. ¿Hubo, como se ha dicho, una tentativa deliberada para resucitar el paganismo sobre los restos de los mitos judeocristianos?...Dicho de otra forma, lo que los artesanos del 'compromiso eusebiano' habían creado, integrar la historia universal en la tradición bíblica dominante, lo que hará Bossuet con brillantez, ¿es demolido de forma sistemática por los filósofos? Si admitimos que la respuesta es sí, conviene recordar que los hombres cultos tenían a su disposición desde el siglo XV la mitología antigua, de la que podían hacer los usos más heterogéneos...La cuestión planteada por los propios cristianos, y luego por sus adversarios, es la de la unidad de la historia religiosa de la humanidad, en el espacio desmesuradamente agrandado después de los grandes descubrimientos." 4

Así, para Pierre-Daniel Huet -obispo de Avranches- los dioses antiguos son los herederos deformados de la revelación bíblica, tal como expone en su Demonstratio Evangélica (1680), y los mexicanos son -como ya sostuvo López de Gomara- descendientes de los atlantes. En 1726 Claude Olivier restaura la vieja idea que hace de la Atlántida una descripción encubierta de Palestina, idea ya presente en Cosmas Indicopleustes. En el mismo sentido se manifestará JacquesJulien Bonnaud en 1786 en una obra cuyo título lo dice todo: Hérodote historien du peuple hébreu sans le savoir.

\section{De la Ilustración al Romanticismo}

Pero también existen en el mundo ilustrado concepciones sobre la Atlántida que no son bíblicas ni nacionalistas. Court de Gébelin publicó entre 1773 y 1782 los nueve volúmenes de su Monde Primitif, donde sostiene que la civilización surge simultáneamente en China, la India y el Próximo Oriente, pero proviene de un origen común: esa Atlántida de que nos habla Platón y que no es más que el recuerdo de una primigenia edad de oro. Y en su Essai sur les Moeurs (1769) Voltaire relaciona el relato platónico con el oscuro recuerdo de unas descubiertas y luego olvidadas islas Madeira, con lo cual enlaza con las hipótesis ya mencionadas de Kircher y en general con la tesis de que los archipiélagos que conforman la Macaronesia constituyen los restos del antiguo continente hundido.

También el siglo XVIII tuvo representantes de la hipótesis que relaciona el relato platónico con el Diluvio, sea en versiones fideistas o laicas. Nicolas Boulanger (1722-1759) sostuvo que toda la historia de la humanidad gira alrededor de sucesivos diluvios y que el fin de la religión es disfrazar el temor a la repetición de

4 Ibid., pp. 87-88. 
los sucesivos desastres. Hay un eterno retorno del hecho diluvial, y el gran secreto del cosmos es que la naturaleza se revuelve cíclicamente contra el género humano. $\mathrm{Y}$ ese es el valor del relato de Platón, su carácter de advertencia.

Y en pleno viraje desde la Ilustración hasta el Romanticismo se inscriben también las obras de William Blake (1757-1827), que sostuvo que Inglaterra era heredera de la Atlántida a la vez que el país de las tribus de Israel. Wilford publicó un ensayo en 1805 donde se argumenta que las blancas y lejanas islas occidentales de las que se habla en los Puranas son en realidad Gran Bretańa y la Atlántida. Mientras tanto, el irlandés Henry O'Brien afirmó en 1834 que el budismo era la religión de los primeros hombres e Irlanda una colonia atlante. En una línea más racionalista se sitúa la postura de Jean-Antoine Letronne (1787-1848), que si bien considera el relato de la Atlántida una fábula le adscribe una procedencia egipcia.

Lo cierto es que el positivismo decimonónico contribuyó en gran medida a que el tema de la Atlántida se fuese deslizando desde la investigación históricofilosófica más o menos seria hacia el terreno de la literatura. De este modo Népomucène Lemercier (1771-1840) compuso un poema en 1812 cuya última parte está dedicada a la Atlántida, mientras Julio Verne (1828-1905) describirá la ciudad sumergida en sus Veinte Mil Leguas de Viaje Submarino (1869) y el catalán Jacint Verdaguer (1845-1902) redactará en 1877 una epopeya con el título de la mítica ciudad platónica.

\section{Ignatius Loyola Donnelly}

Antes de hablar de los personajes relacionados con la Atlántida en el siglo XX es inevitable referirnos a Ignatius Loyola Donnelly (1831-1901). Militó en el partido republicano y, tras una fallida experiencia de construcción utópica de una ciudad llamada Niningir City, ocupó el cargo de vicegobernador del Estado de Minnesota. Alcanzó más tarde un escańo como congresista, que logró revalidar hasta que la guerra civil truncó su carrera política. Pero la abogacía y la política no fueron ni mucho menos sus únicas preocupaciones.

"También era un gran aficionado a la novela, a los libros históricos y a los ensayos. Puede decirse que entre sus pasiones se encontraba la arqueología y la geología, lo que le había llevado a participar en diferentes excavaciones dentro de su Estado. Sus biógrafos cuentan que durante el tiempo que permaneció en Washington era un asiduo visitante de la Biblioteca del Congreso...Cierto día de 1870 cayó en las manos de Donnelly la novela 'Veinte mil leguas de viaje submarino' de Julio Verne, que leyó con verdadera fruición. Y nada más llegar al pasaje en que los tripulantes del 'Nautillus' descubren 
los restos de la Atlántida, se sintió atrapado por el tema. A partir de entonces se cuidó de reunir un gran número de libros sobre el continente perdido. Al cabo de unos diez años pudo verse rodeado de la mayor biblioteca sobre la Atlántida. No había dejado de leer todos los libros, artículos y estudios, cuando decidió escribir su propia obra. Mientras lo hacía, no dejaba de solicitar a los libreros conocidos que le consiguieran lo que se fuera publicando sobre el tema." 5

Donnelly entendió perfectamente que el análisis del problema conllevaba la necesidad de afrontar una visión multidisciplinar del objeto de estudio:

"Entre el material que manejaba incluyó los temas relacionados con el continente perdido: mitología, geografía, historia universal, religión, geología, literatura antigua, etc. Ningún terreno dejó sin explorar, y hasta se introdujo en cuestiones que rozaban las supersticiones, el esoterismo y lo sobrenatural." ${ }^{\prime 6}$

Con un enorme éxito de acogida entre el público apareció en 1882 su obra Atlantis: The Antediluvian World. En ella Donnelly utiliza la Atlántida como hipótesis de resolución de toda una serie de enigmas relacionados con los más diversos campos del saber. Utiliza la fórmula consistente en asignar a cualquiera de los problemas históricos una fuente de resolución común: la Atlántida. De ese modo liga el relato platónico con el lugar de aparición de la civilización, con el centro neurálgico o civilización madre que colonizó el mundo entero en una peculiar primera globalización protohistórica, fundamento de las leyendas sobre el paraíso de las distintas mitologías y base histórica en la que se basarían las religiones de la antigüedad; además de proporcionar la explicación de las evidentes semejanzas existentes entre las religiones egipcia y andina así como fenómenos como el piramidismo y la momificación, la fuente del trabajo con los metales, el problema de la lengua madre y del origen de la escritura, la sede de los pueblos indoeuropeos y semitas, así como el enigma de la universalidad de mitos sobre el diluvio existentes en todo el planeta.

Es esta estrategia de investigación la que hace de Donnelly el padre de la atlantología moderna, pues al situar la isla-continente en el origen de resolución de los problemas no resueltos por el paradigma dominante en las ciencias históricas, sustituye la búsqueda de una base real que fuese correlato objetivo del relato de Platón por el establecimiento de una hipótesis que sostiene la existencia

5 Barceló, Carlos: La Atlántida. Edimat Libros. Madrid, 1998, pp. 151-152.

6 Ibid., p. 152. 
de una perdida civilización primigenia como punto de partida del resto de manifestaciones culturales humanas. Es ese el sendero que seguirá la moderna arqueología de culto de la mano de figuras como J. A. West, Graham Hanckock, Robert Bauval o R. Sckoch -éste último ciertamente difícil de encuadrar entre lo académico y lo heterodoxo-.

Otro curioso personaje de nuestra saga lo encontramos en la persona de la rusa Helena Petrovna Hahn (1831-1891), más conocida como Madame Blavatsky -apellido adoptado de un primer y fugaz matrimonio-. Tras fundar el movimiento teosófico en Rusia en 1858, en 1871 viajó a Estados Unidos, donde conoció las ideas de Donnelly, y fundó junto a Henry Steel Olcott la llamada Sociedad Teosófica (1875), dedicándose mediante el ocultismo y el esoterismo a investigar temas como las pirámides o el origen del universo y del ser humano. Escribió un libro en dos tomos, La Doctrina Secreta, donde trata de las ciencias ocultas basándose en un misterioso Libro de Dzyan que sólo ella parecía conocer. Entre sus afirmaciones se encuentra la de que había logrado establecer contacto con espíritus procedentes de la Atlántida y Lemuria. Fue tildada de farsante por la prensa india y la londinense Sociedad para la Investigación en Física.

\section{Atlantis en el Siglo XX}

Ya en el siglo XX personalidades de la relevancia de Adolf Schulten identificará la Atlántida con Tartessos y la situará en la desembocadura del Guadalquivir, mientras el novelista Pierre Benoit la ubicará en el Sahara y el alemán Leo Frobenius en Níger. Lo cierto es que mientras en Francia el asunto estuvo restringido al campo literario no ocurrió lo mismo en Alemania, donde el relato platónico fue utilizado como pretexto para la justificación de las ideas de la supremacía aria que terminarían desembocando en la pesadilla nazi. Hemos de mencionar la obra de Karl Georg Zschaetsch titulada La Atlántida, Patria Primitiva de los Arios (1922) y la de Albert Hermann Nuestros Antepasados y la Atlántida (1934), que habla de un imperio germano-atlante cuya prueba son los megalitos. En El Mito del Siglo XX (1932) Rosenberg dice que la colonización atlante alcanzó el mundo entero e incluyó a Judea. Y en los años cincuenta escribió varias obras siguiendo esta tradición el pastor alemán Jurgen Spanuth, que identifica la capital atlante -a la que denomina Basileia- con Heligolandia, adscribiéndose así a la que se denomina tesis hiperbórea.

Relacionado con lo que Berlitz denomina historia intuitiva, Richard Ellis dice lo siguiente:

"Es obvio que hay un sinfín de teorías relativas a las ubicaciones y el origen de la Atlántida. Pero hay otra clase de 'atlantología' en la que místicos y videntes prescinden de frivolidades tales como la historia, la geografía o la arqueología y afirman 'saber' de la 
Atlántida. El número de libros que ha escrito la fraternidad de lo paranormal -Edgar Cayce se enteró de la existencia de una Atlántida de cincuenta mil años de antigüedad que le describieron personas que habían sońado con ella- es virtualmente infinito $y$, en muchos casos, hablar de ellos sería atribuirles una credibilidad que en su mayor parte no merecen. Sin embargo, es frecuente encontrar obras sobre la Atlántida en la sección de 'Ocultismo' o 'Nueva Era' de las librerías, y, por tanto, no podemos prescindir totalmente de este fenómeno.” (Ellis, 1998, p. 89)

Nos interesa el asunto no sólo por constituir un hecho editorial indiscutible, sino porque ilustra la idea acerca de cómo del relato de Platón han ido surgiendo versiones hasta conformar un mito a veces bastante alejado del texto original del autor ateniense. Pero sigamos el curso histórico de aparición de los atlantólogos. El mitólogo, periodista y poeta escocés Lewis Spence (1874-1955) es considerado discípulo de Donnelly y publicó varios libros sobre el tema de la Atlántida, entre ellos The Problem of Atlantis (1924) y el póstumamente publicado The History of Atlantis (1968). Parece que su intención fue dar una base más científica a las hipótesis lanzadas por Donnelly. Por ejemplo, intentó asentar sobre datos geológicos la existencia de una gran masa terrestre en el Atlántico durante el Terciario.

La teoría de la deriva continental, formulada por Alfred Wegener en El Origen de los Continentes y Océanos (1915) -universalmente rechazada por la comunidad científica en un principio y hoy día convertida en uno de los dogmas indiscutibles del actual paradigma dominante en geología-, originó una controversia enorme hasta su aceptación generalizada. En lo que toca al tema de la Atlántida, la cuestión de la deriva continental la afecta en el siguiente sentido: si es cierto que los continentes se desplazan -en realidad lo hacen las placas tectónicas sobre las que estos se asientan-, ¿hay lugar en el Atlántico Norte para que el "encaje" entre Europa y Norteamérica deje el suficiente espacio como para haber permitido la existencia de una masa de tierra como la que Platón describe en el Timeo y el Critias? Y como todo en este tema esa pregunta vuelve a conducirnos a una exégesis del texto platónico, ya que cuando habla del hundimiento es preciso averiguar si se refiere el filósofo ateniense a la totalidad del territorio atlante o solo a su capital.

Además de apoyarse en las tesis expuestas, Spence siguió a su maestro Donnelly en la ubicación posible de la Atlántida, a saber, la cordillera del Dolphin's Ridge, situada en el centro del Atlántico Norte, y que en forma de óvalo alargado se extiende desde las Azores hasta América del Sur. Tras intentar refutar la tesis egea

7 Ellis, Richard: En Busca de la Atlántida. Grijalbo. Barcelona, 1998, p. 89. 
sobre la Atlántida, Spence sostuvo que la influencia atlante se habría extendido a ambos lados del Atlántico, tanto sobre los egipcios como sobre los mayas.

En Estados Unidos nació Edgar Cayce (1877-1945), uno de los videntes más famosos de la historia, que al parecer desde muy joven tenía la facultad de referir en sueños provocados hipnóticamente remedios a ciertas enfermedades así como más tarde descripciones de sus anteriores reencarnaciones. Han quedado registradas hasta un total de 672 visiones de Cayce sobre la Atlántida, en las que entre otras cosas determinó su posición geográfica entre el Golfo de México y el Mediterráneo, así como la existencia de tres grandes periodos catastróficos de desmembramiento -el último hace 11.000 años- o el hecho de que fuese una civilización bastante parecida a la del siglo XX, capaz de generar electricidad -mediante una piedra llamada refractaria- y construir aeronaves. A todo esto Cayce unió la predicción de que Atlántida -Poseidia la denominaba él- reaparecería en la década de los sesenta en el Caribe, concretamente cerca de Bimini.

$\mathrm{Y}$ durante años se organizaron varias expediciones a las Bahamas con el apoyo del Instituto Cayce de Virginia Beach y, como confirmando la profecía, unos buzos descubrieron en 1968 una formación submarina semejante a una autopista construida a base de grandes bloques rectangulares de piedra. La Asociación para la Investigación y la Iluminación, fundada por Cayce, vio en ello la prueba del cumplimiento de la profecía del desaparecido vidente, en contra de la opinión de los arqueólogos profesionales, que ven en esas formaciones el producto de procesos geobiológicos naturales. De la misma opinión que el vidente fue uno de sus adeptos, David Zink, que organizó tres expediciones al lugar entre 1975 y 1977. Nótese que Cayce introduce una nueva vuelta de tuerca en el proceso de conformación del mito de la Atlántida, pues al giro que realizó Donnelly desde el relato platónico hasta una supuesta civilización originaria, añade nuestro vidente la idea de que además dicha hipotética metrópoli poseía un grado de desarrollo científico-tecnológico aún hoy no alcanzado. Y, por cierto, una de sus afirmaciones ha dado lugar a un desarrollo de la investigación atlantológica reciente de insospechado interés y a la que nos referiremos más adelante. Se trata de la aseveración de Cayce de que los supervivientes se extendieron por diversas partes del mundo y que cuando llegaron a Egipto habían enterrado sus archivos más importantes en una Sala de los Escritos ubicada bajo las patas de la Esfinge de Gizeh.

En esta relación de atlantólogos no puede faltar la fascinante figura del coronel Percy Harrison Fawcett, geógrafo y aventurero de extraordinario prestigio. En 1928 emprendió una aventura de la que jamás regresaría, al internarse en la selva amazónica camino del Mato Grosso con objeto de alcanzar la que denominaba ciudad $Z$, uno de los vestigios de antiguas construcciones prehistóricas que las leyendas indias situaban en el corazón de Brasil. 
En 1925 apareció El Relato de la Atlántida y la Lemuria Perdida, del coronel, y miembro de la Sociedad Teosófica fundada por Blavatsky, William Scott-Elliott. En la obra se sostiene que los atlantes vivían en una sociedad aristocrática rodeada de prodigios tecnológicos, entre ellos las ya mencionadas aeronaves, y contaban con cinco millones de años de historia hasta que desaparecieron en una última y cuarta catástrofe en el 11564 AP. Otro discípulo de Blavatsky fue Rudolf Steiner (1861-1925), que formó su propio movimiento espiritual -al que denominó antroposofía-, y que se apoyó en las ideas de Scott-Elliot para afirmar que el continente atlante se hallaba sumergido entre Europa y América, en el fondo del océano Atlántico.

Siguiendo nuestro periplo por la serie de autores que han prestado atención al tema de la Atlántida, toca mencionar al autor con algunas de cuyas ideas comenzamos el presente artículo. Charles Berlitz se hizo mundialmente famoso por la publicación en 1974 del libro The Bermuda Triangle, donde sostiene la existencia de una zona en el Atlántico donde barcos y aviones desaparecen al parecer sin explicación alguna y que muy bien hubiera podido tragarse también a un continente, apoyando sus afirmaciones sobre la desaparición de la Atlántida en la zona en las exploraciones de Zink y en las visiones de Cayce entre otros. Ha dedicado dos libros específicos al tema de la Atlántida: El Misterio de la Atlántida (1969) y Atlántida: el Octavo Continente (1984), donde sostiene que los archipiélagos que conforman la actual Macaronesia son las cumbres del continente hundido y que la proliferación de tesis dispares sobre su ubicación a lo largo de todo el mapamundi no es sino prueba de que llegó a constituir una civilización mundial.

Gran repercusión tuvo también un libro del que Albert Einstein dijo "No, realmente no es un mal libro. Lo único malo que tiene es que es un locura". Nos referimos al gran éxito editorial que fue en su momento Worlds in Collision, publicado en 1950 y obra del médico y cosmólogo aficionado de origen rusoisraelí Immanuel Velikovsky, quien sostuvo que tanto el relato de la Atlántida como otros muchos textos antiguos hacen referencia en realidad a una serie de catástrofes de origen planetario -provocadas por los actuales planetas Venus, en principio un cometa, y Marte- a mediados del segundo milenio y hacia la primera mitad del primero antes de nuestra era. En lo que respecta a nuestra investigación, uno de los temas por el que nos interesa la obra de Velikovsky es por su idea de que la fecha en que Platón fija el conflicto heleno-atlante ha de contener un error, y para hacerla aceptable a la historiografía actual se precisa reducir un cero a la cifra de nueve mil años. Este procedimiento de manipulación descarada del texto platónico para hacerle decir lo que no dice es muy habitual en los investigadores que se han ocupado de la Atlántida, tanto los intuitivos como los respetables. 
Por su parte, Otto Muck (1892-1956), piloto de aviación e ingeniero inventor de innovaciones tecnológicas para los submarinos, escribió El Secreto de Atlántida, donde sostiene que en el lugar donde la corriente del Golfo se encuentra con la cordillera central submarina del Atlántico existe una gran isla sumergida que no es otra que la Atlantida de Platón. Además piensa que las tesis de Wegener dejan espacio suficiente en el Atlántico Norte para la existencia de un pequeńo continente, pues Europa y América del Norte no encajan tan perfectamente como lo hacen África y América del Sur. En cuanto a la razón del hundimiento, Muck introduce la hipótesis de un asteroide como causante de la catástrofe.

Otro de los autores a los que ya hemos hecho referencia es el pastor protestante Jürgen Spanuth, en cuya obra Atlantis of the North (1979) se reafirma en lo dicho en anteriores escritos suyos de los años sesenta. Básicamente su propuesta consiste en identificar -a partir de la invasión de los pueblos del mar a mediados del primer milenio antes de nuestra era, documentada en los textos y jeroglíficos egipcios- a los atlantes con habitantes del mar del Norte y no con navegantes procedentes del Mediterráneo o del Atlántico. Con ello culmina la tradición de lo que denominaremos tesis hiperbórea sobre la existencia de la Atlántida, profundamente enraizada según Vidal-Naquet en una tradición germánica encaminada a demostrar la superioridad de la raza aria y el origen no judío de los pueblos indogermánicos.

Por cierto, Spanuth recurre también al procedimiento de reducir la fecha del 9.000 hasta aproximadamente el 1200 a. C. para soslayar la incómoda datación que aparece en el texto platónico. Es curioso que el mismo método sea utilizado por personajes como Blavatski -aunque esta multiplica por diez para alcanzar los 900.000 años- pero también por los muy respetables científicos defensores de la hipótesis egea como Galanopoulos o el mismísimo J. V. Luce. Vaya por delante que dicho hábito va a resultar ser una constante en las diversas hipótesis existentes acerca de la existencia y ubicación de la isla imperial: cada cual "arrimará el ascua a su sardina”, como suele decirse, y tomará aquellos pasajes que encajen con su hipótesis para pasar sin solución de continuidad a descartar e incluso deformar los que no resultan adecuados para el mismo fin.

En otro orden de cosas, Richard Ellis nos dice estas palabras en referencia a los autores que se ocupan de la problemática referente al mundo hundido de que nos habla Platón en el Timeo y el Critias:

"Hace mucho tiempo que lo que se ha escrito sobre la Atlántida desde Platón se hubiera relegado a la sección de la biblioteca reservada para 'charlatanes y lunáticos' si se limitara a hablar de colisiones planetarias, jarrones con cabeza de búho, reencarnaciones o bananas. Aunque algunas de estas obras parecen ciencia ficción pura y simple, sus autores -que nosotros sepamos- pretenden que las consideremos 
interpretaciones objetivas de los datos disponibles. Pero en el caso de los oceanógrafos, geólogos, ingenieros y arqueólogos respetables que en nuestro tiempo también han escrito sobre la Atlántida necesitamos ver las cosas de otra manera, examinar los datos y las interpretaciones a la luz de la ciencia."

Entre esos autores respetables incluye Ellis a Rachel Carson, que en 1951 publicó un libro titulado The Sea Around Us donde relaciona la leyenda de la Atlántida con la elevación y posterior hundimiento de la tierra en la zona del Mar del Norte conocida como Dogger Bank. En 1950 Spyridon Marinatos sostuvo que la leyenda platónica era resultado de una síntesis de diversas tradiciones históricas, entre las que había una leyenda que databa del Imperio Medio de Egipto sobre un naufragio en una isla perdida y una crónica sumeria de la inundación a que se refiere la Biblia. Asimismo sostuvo la tesis de que una erupción volcánica fue la responsable de la destrucción de la civilización minoica de Creta. Y fue un artículo publicado en 1960 por Angelos Ganalopoulos el que relacionó el relato de la Atlántida y el diluvio de Deucalión con la erupción volcánica de Santorín en la edad del Bronce -esa sería la misma erupción que causó las plagas bíblicas sobre Egipto, el fenómeno de la separación de las aguas en tiempos de Moisés, y el mito griego de Faetón-. Un partidario de esta tesis egea es el ingeniero oceanográfico James Mavor, quien entre 1966 y 1984 publicó una serie de libros y artículos donde se adhirió a las ideas de Marinatos y Ganalopoulos para terminar al final por sugerir la sustitución de la erupción por un meteorito, cometa o asteroide que chocó con la Atlántida egea. En apoyo de esta última hipótesis cita a estudiosos como Otto Muck o Inmanuel Velikovski, que -como ya hemos visto- en los años cincuenta habían sostenido tesis parecidas. Otros especialistas como Charles Pellegrino o Jacques Cousteau se han adherido con más o menos matices a la tesis egea, cuyo origen se halla en dos artículos publicados en Febrero de 1909 en el diario Times por el erudito inglés K. T. Frost. En ellos este autor propone la Creta minoica como modelo de la Atlántida, vía una narración egipcia del auge y la caída de dicha civilización mediterránea.

Un estudioso como el geoarqueólogo suizo Eberhard Zangger publicó en 1992 un libro titulado The Flood from Heaven, donde sostiene que la narración que refirieron a Platón era en realidad un visión egipcia deformada de la guerra de Troya. El arqueólogo británico Peter James escribió en 1995 un libro titulado The Sunken Kingdom: The Atlantis Mystery Solved, donde argumenta que Atlantis se encontraba en la península de Anatolia, cerca de la actual Esmirna. Y en 2001 el geólogo Jacques Collina-Girard ha sugerido que Platón pudo referirse a un pequeño archipiélago situado al oeste del estrecho de Gibraltar. Sin que debamos

9 Ellis, Richard: En Busca de la Atlántida. Op. cit., p. 105. 
de olvidar tampoco la hipótesis formulada por el físico alemán Rainer W. Kühne en 2004 acerca de que la fabulosa metrópoli descrita por Platón se encuentra ubicada en pleno corazón del Parque Nacional de Doñana.

\section{Atlantis y la Arqueología de Culto}

Graham Hancock conforma junto a Robert Bauval, Jhon Anthony West, Robert Temple y más recientemente Robert M. Schoch, el grupo de representantes más significativos de lo que se ha dado en llamar la arqueología de culto, movimiento que propone una alternativa al paradigma científico dominante en las ciencias históricas y arqueológicas mediante una reinterpretación de ciertos puntos de dicho paradigma, para terminar abogando por la existencia de una supuesta civilización mundial preneolítica cuyos vestigios podemos encontrar principalmente en el antiguo Egipto. Atlántida sería en este contexto el nombre que recibió en la antigüedad el recuerdo de esa primigenia civilización mundial.

Y por la gran repercusión que ha tomado entre las últimas teorías atlantológicas, no podemos dejar de mencionar una hipótesis que relaciona a la Atlántida con la Antártida. A raíz de una interpretación ciertamente original del mapa que en 1513 elaboró un navegante turco conocido como Piri Reis y que apareció en el siglo XX en la Biblioteca del Congreso de los Estados Unidos y otros documentos similares se sostuvo que reproducían una Antártida libre de hielos, luego debían de ser copias de testimonios de una era antiquísima. Fue el profesor de historia y ciencia de New Hampshire Charles Hapgood quien en 1955 formuló la tesis de que la corteza de la Tierra se desliza, intacta, alrededor de un núcleo sólido. En 1970 publicó The Path of the Pole, donde perfiló su teoría de que un desequilibrio de la capa de hielo de la Antártida afectó a la rotación de la Tierra y alteró la posición de los polos. En 1966 había publicado Maps of the Ancient Sea Kings: Evidence o fan Advanced Civilization in the Ice Age, donde expone la idea de que existió una civilización de ámbito mundial antes de la última glaciación. Autores como el matrimonio Flem-Ath y más recientemente Graham Hancock han utilizado la obra de Hapgood para hablar de una Atlántida antártica.

Quizá la más peculiar de estas teorías sea la que sostiene Robert Temple, profesor asociado de Humanidades, Historia y Filosofía de la Ciencia en la Universidad de Louisville, experto en lenguas antiguas y un especialista en la historia de la ciencia china. En el año 2000 publicó un fascinante estudio sobre historia de la tecnología en las civilizaciones antiguas, concretamente referido a la ciencia de la óptica, titulado The Crystal Sun -"El Sol de Cristal"-.Y mucho antes, en 1976, apareció The Sirius Mystery -"El Misterio de Sirio"-, donde a partir de los conocimientos astronómicos sobre la estrella Sirio que posee el pueblo africano de los dogon elabora una teoría sobre la visita de seres alienígenas procedentes de la mencionada estrella. Su posición respecto del tema de la Atlántida va ligada a esta presencia extraterrestre del siguiente modo: 
"En su libro West declara que la civilización egipcia no se desarrolló, sino que fue un legado. Me siento inclinado a estar de acuerdo con él, por decirlo de un modo elegante... West deja muy claro que cree que esta herencia proviene de una temprana civilización del tipo de la Atlántida originaria de este planeta, y rechaza los argumentos de quienes recurren a los orígenes extragalácticos para explicar la civilización egipcia...siempre sugerí que la hipótesis de la Atlántida era ciertamente una posibilidad alternativa a la hipótesis extraterrestre. El problema es que yo no creo en la viabilidad de la teoría de la Atlántida tal como se postula en la actualidad, pues implica la ausencia de contacto extraterrestre...Pero la Atlántida postulada hoy es demasiado antigua y deja varios miles de años de 'nada' entre ésta y Egipto y Sumeria...En mi opinión, en la antigüedad hubo un contacto de extraterrestres con la Tierra. Y creo que el período de interacción con extraterrestres y la fundación de la civilización egipcia y sumeria, probablemente con su ayuda, ocurrieron entre los años 5000 y 3000 a. C." ${ }^{10}$

En el texto anterior Temple alude a John Anthony West, una especie de guía turístico experto en algo llamado egiptología simbólica, que en Serpent in the Sky. The High Wisdom of Ancient Egypt (1993) -"La Serpiente Celeste"- sostiene entre otras cosas que la erosión sufrida por la Esfinge procede del agua y no del viento -idea que extrae de la obra de Schwaller de Lubicz-. De ese hecho infiere que ese agua procedía de lluvias torrenciales que en Egipto no se producen desde al menos el quinto milenio antes de nuestra era, luego la Esfinge es miles de años anterior a las pirámides y producto de una civilización predinástica. De la misma opinión es el geólogo y profesor universitario Robert M. Schoch, que sostiene sus tesis en dos libros: uno publicado en 1999 y titulado Voices of the Rocks - Escrito en las Rocas"- y otro aparecido en 2003 bajo el título de Voyages of the Pyramid Builders -"Los Viajes de los Constructores de Pirámides"-, en los cuales comienza basándose en la redatación de la Esfinge y termina concluyendo que el desastre al que alude Platón se refiere a una catástrofe producida frente a las costas de Sumatra.

La Esfinge juega en todo este asunto un papel fundamental, y de hecho en una obra escrita por Robert Bauval y Adrian Gilbert y titulada El Misterio de Orión se sostiene que la altiplanicie de Gizeh es un reflejo de una porción del cielo y que las tres grandes pirámides son un reflejo arquitectónico del cinturón de Orión. Más fundamental es aún su papel en la obra de 1996 que Bauval escribe junto con Hancock y que lleva por título Keeper of Genesis. A Quest for the Hidden Legacy

10 Temple, Robert: El Misterio de Sirio. Timun Mas. Barcelona, 1998, p. 21. 
of Mankind -"El Guardián del Génesis. La Búsqueda del Legado Oculto de la Humanidad"-, donde se dice que la Esfinge señala una correlación estelar que nos retrotrae al año 10.500 antes de nuestra era, un tiempo primero donde ha de fecharse la desaparición de una civilización primordial de la que son herederos los antiguos egipcios.

Y para que quede claro que en muchas ocasiones la pretendida tajante división entre iluminados por un lado e investigadores serios por otro no está nada clara en este asunto, digamos de pasada que en el libro de Bauval Secret Chamber. The Quest for de Hall of Records (2001) - "La Cámara Secreta"- se nos refiere la trayectoria de uno de los egiptólogos más reputados y defensor acérrimo del paradigma oficial: nos referimos a Mark Lehner. Pues bien, resulta que nuestro investigador serio comenzó su carrera financiado por la Fundación Edgar Cayce para buscar bajo las patas de la Esfinge nada menos que la Sala de los Archivos que el famoso vidente dijo que los atlantes habían guardado en aquel lugar. Y también en este curioso libro se habla de los contactos existentes entre el hijo mayor de Cayce y nada menos que el conservador oficial de la meseta de Gizeh, el famoso doctor Zahi Hawass.

\section{Algunas Conclusiones}

Tras este recorrido histórico vemos como el de la Atlántida puede considerarse un relato-problema que ha cumplido diversas funciones a lo largo de una dilatada historia que ya cuenta con veinticinco siglos de existencia, una de ellas sin duda la de cuestionar los paradigmas existentes en diversas épocas de la historia humana. De ese modo el relato platónico sobre la Atlántida, utilizado por el propio Platón como una especie de contraejemplo para definir a la Atenas primitiva y su concepción de lo que era un estado ideal, ha desempeñado una diversa gama de papeles dentro del contexto espaciotemporal en que se han ido sucediendo los distintos paradigmas dominantes.

De esa forma, mientras en la Edad Antigua sirvió de apoyo a los conocimientos y especulaciones geológicas acerca de los cambios producidos en la correlación de tierras emergidas con respecto a los dominios del agua en el mundo, a finales de la Edad Media actuó como estímulo a la ampliación de horizontes geográficos y a la exploración marítima que se materializaría a partir del Renacimiento.

Y en la Edad Moderna coadyuvó al descubrimiento de nuevas tierras y sirvió de justificación ideológica al imperialismo español, para en la Edad Contemporánea ser puesto al servicio de los objetivos de diversos nacionalismos, así como para introducir la hipótesis de una civilización primigenia preneolítica -en algunas variantes altamente desarrollada tecnológicamente-, además de proporcionar un marco temporal alternativo al suministrado por el estrecho marco temporal que la tradición bíblica asignaba a la historia humana y del mundo. Sin olvidar que también ha sido explotado por la corriente esotérica y mística como reacción 
al saber científico, e incluso ha sido utilizado por ideologías totalitarias para justificar sus delirios de poder.

Para terminar este artículo podríamos preguntarnos por el papel que el relato platónico sobre la Atlántida puede jugar en la actualidad. Entendemos que, a tenor de lo expuesto en las páginas anteriores, podríamos consignar al menos cinco puntos en los que podría contribuir a la articulación de un conocimiento histórico más preciso de los hechos humanos.

1. Acabar con la especialización meramente descriptiva gracias a su carácter interdisciplinar.

2. En su versión popularizada, constituye un aglutinante de hechos que desafían la explicación proporcionada por el paradigma dominante. Podemos poner como ejemplo la fecha del descubrimiento de América o la cuestión acerca de la antigüedad del hombre americano.

3. Detectar problemas ignorados por los presupuestos teóricos del paradigma vigente, como por ejemplo la existencia de pirámides tanto en el Viejo como en el Nuevo Mundo.

4. Constituir una fuente de inspiración para la elaboración de una teoría alternativa al paradigma establecido en la actualidad.

5. Proporcionar un ejemplo histórico real del papel que juega el estrato ideológico en la evolución de la sociedad humana, según un esquema por el cual a partir de la Edad Moderna una innovación tecnológica como la aparición de la brújula se incardina en un proceso socioeconómico tendente a buscar nuevas tierras donde obtener materias primas, para lo cual a nivel político e ideológico se reconvierten elementos preteridos -o que jugaban un papel secundario- en la Edad Media, como el relato platónico de la Atlántida. 